\title{
BMJ Open Mapping the risk perception and communication gap between different professions of healthcare providers in cancer care: a cross-sectional protocol
}

\author{
Trine Stub, ${ }^{1,2}$ Frauke Musial, ${ }^{1}$ Sara A Quandt, ${ }^{2}$ Thomas A Arcury, ${ }^{3}$ \\ Anita Salamonsen, ${ }^{1}$ Agnete Kristoffersen, ${ }^{1}$ Gro Berntsen ${ }^{1}$
}

To cite: Stub T, Musial F, Quandt SA, et al. Mapping the risk perception and communication gap between different professions of healthcare providers in cancer care: a cross-sectional protocol. BMJ Open 2015;5: e008236. doi:10.1136/ bmjopen-2015-008236

- Prepublication history for this paper is available online. To view these files please visit the journal online (http://dx.doi.org/10.1136/ bmjopen-2015-008236)

Received 18 March 2015 Revised 4 August 2015 Accepted 12 August 2015

\section{CrossMark}

${ }^{1}$ Department of Community Medicine, The National Research Center in Complementary and Alternative Medicine (NAFKAM), UiT The Arctic University of Norway, Tromsø, Norway

${ }^{2}$ Department of Epidemiology and Prevention, Division of Public Health Sciences, Wake Forest School of Medicine, Winston-Salem, North Carolina, USA

${ }^{3}$ Department of Family and Community Medicine, Wake Forest School of Medicine, Winston-Salem, North Carolina, USA

Correspondence to

Trine Stub;

trine.stub@uit.no

\begin{abstract}
Introduction: Studies show that patients with cancer who use complementary and alternative medicine (CAM) have a poorer survival prognosis than those who do not. It remains unclear whether this is due to a priori poorer prognosis that makes patients turn to CAM, or whether there is a factor associated with CAM use itself that influences the prognosis negatively. Healthcare providers should assist patients in safeguarding their treatment decision. However, the current non-communication between CAM and conventional providers leaves it up to the patients themselves to choose how to best integrate the two worlds of therapy. In this study, an interactive shared decision-making (SDM) tool will be developed to enable patients and health professionals to make safe health choices.
\end{abstract}

Methods and analysis: We will delineate, compare and evaluate perception and clinical experience of communication of risk situations among oncology experts, general practitioners and CAM practitioners. To accomplish this, we will develop a pilot and implement a large-scale survey among the aforementioned health professionals in Norway. Guided by the survey results, we will develop a $\beta$-version of a shared decisionmaking tool for healthcare providers to use in guiding patients to make safe CAM decisions.

Ethics and dissemination: Participants must give their informed and written consent before inclusion. They will be informed about the opportunity to drop out from the study followed by deletion of all data registered. The study needs no approval from The Regional Committee for Medical and Health Research Ethics because all participants are healthcare professionals. Results from this study will be disseminated in peer-reviewed medical journals.

\section{INTRODUCTION}

Complementary and alternative medicine (CAM) is a popular treatment modality among patients with cancer in Europe. ${ }^{1-4}$ In this research project, CAM, or alternative treatment, is understood as a health-related

\section{Strengths and limitations of this study}

- The study plan in this study is strong, as it combines three different strategies (a literature review, a pilot cross-sectional study and a main cross-sectional study)

- This research strategy was applied with the aim to develop a shared decision making tool.

- There are still some methodological challenges in surveying health care professionals, since oncologists and general practitioners are often poor responders. Therefore, steps must be implemented in order to enhance the response rate.

treatment that is practiced outside the established health services and not practiced by authorised health personnel. However, treatment practiced within the scope of the established health services or by authorised health personnel is also covered by the term alternative treatment when the methods employed are used outside the established health service. ${ }^{5}$ Findings from studies suggest that, on average, half of all patients with cancer use CAM, and this proportion has increased over the past years. ${ }^{6}$ The Norwegian Cancer Society stated that approximately $50 \%$ of all Norwegian patients with cancer used CAM in $2008 .^{7}$ The majority of patients with cancer use CAM because they believe it increases the body's ability to fight the cancer, strengthens the immune system, improves physical and emotional well-being and quality of life or enables the maintenance of hope and control over their cancer care. ${ }^{8} 9$ Although current RCT-based documentation of CAM treatment gives little support to patients' beliefs of CAM's efficacy on tumours, ${ }^{10}$ a large number of patients still clearly wish to use CAM. The interpretation of this paradox is that either the patients do not give credence to scientific 
evidence, or they experience some other benefit from the treatment. Objectively, data show that patients with cancer who use CAM have a poorer survival prognosis than those who do not use CAM. ${ }^{11} 12$ It remains unclear whether this is due to a priori poorer prognosis that makes patients turn to CAM, or whether there is a factor associated with CAM use itself that influences the prognosis negatively.

In Norway patients receive conventional medical treatment within the public healthcare system, while CAM practitioners operate outside this system. The majority of the CAM practitioners are members of professional associations that require professional standards of medical and CAM-specific skills of their members. However, patients themselves generally cover the costs of visiting a CAM practitioner. Thus, the Norwegian context is comparable to that of other western settings. ${ }^{13}$ Masseurs, acupuncturists, hands on healers and reflexologists are the CAM practitioners most used by patients with cancer.

Qualitative research into patients' experiences with CAM underlines patient disenchantment with the conventional healthcare system as an important reason for choosing CAM. ${ }^{14}$ Patients emphasise the experience of a fragmented and specialised system, with short consultations in a 'production line' approach, which often compromises continuity at the organisational, informational and relational levels. ${ }^{15}$ In conventional care the patient's 'whole story' may fade and become invisible to the individual practitioner. ${ }^{16}$ CAM practitioners claim to have a more holistic approach. ${ }^{17}$ They often offer therapy directed at both mind and body. ${ }^{18}$ Practicing principles in CAM may include patient-centeredness, empowerment and self-management. ${ }^{19}{ }^{20}$ Thus, it is plausible that CAM supports continuity in the provider/patient relationship to a greater degree than conventional care.

In this research project, risk will generally be defined as a compound measurement of the probability of an event and the magnitude of the potential negative outcome of that event, ${ }^{21}$ both operationally and methodologically. Patient safety is understood as the reduction of risk of unnecessary harm associated with healthcare to an acceptable minimum. ${ }^{22}$ Medical science risk can be divided into direct and indirect risk ${ }^{2324}$ as illustrated in figure 1.

Direct risk is caused by the treatment itself. This dimension includes traditional adverse effects of an intervention, such as bleeding in response to acupuncture needling, nausea caused by chemotherapeutic medication or the adverse effect of an herb, as well as risk connected to self-management advice from the practitioner. ${ }^{25}$ For example, patients with breast cancer often use herbal supplements, such as ginseng or soy products, in conjunction with conventional cancer treatment. ${ }^{26} \quad 27$ These supplements have phytoestrogen components that may alter oestrogen levels or activate oestrogen receptors as either proestrogen or antioestrogen. ${ }^{28}$ High oestrogen levels are well-documented risk factors for breast cancer. Studies of these supplements are mixed, showing increased, ${ }^{29}$ reduced ${ }^{28}$ or no association with circulating levels of oestrogen. ${ }^{30}$

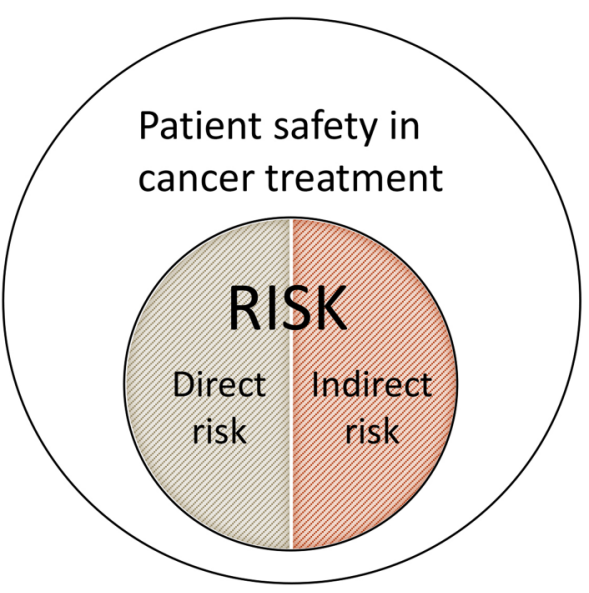

Figure 1 Understanding of patient safety and risk in this research project. Direct risk is caused by the treatment itself and related to the intervention, while indirect risk is related to the treatment context, such as the practitioner more than the medicine.

Indirect risk is related to adverse effects of the treatment context, for example, the CAM practitioner rather than the medicine. A patient may be harmed by a care context that prevents the patient from receiving the best possible treatment relevant to her or his health needs. ${ }^{31}$ A homeopath without appropriate medical training may overlook a serious condition and continue treatment, even in cases where conventional treatment would be an unconditional necessity. This situation may delay meaningful diagnostic procedures and relevant therapeutic interventions.

To ensure patient safety and avoid undesired outcomes, conventional care should assist patients in safeguarding their treatment decisions. This can best be achieved through open, transparent, non-judgmental and informed discussions about possible outcomes of combining CAM and conventional treatment for cancer. Patients with cancer highly value the input from their physicians about the use of CAM. ${ }^{9}{ }^{14}$ Patients should feel free to discuss all the options in their care without the fear of being rejected. Research shows, however, that patients fear that healthcare providers are indifferent or will object to the use of CAM. ${ }^{32}$ It is, therefore, important that healthcare providers initiate this discussion and include this in the history taking. ${ }^{33-35}$ However, studies reveal that $38-60 \%$ of patients with cancer use CAM without informing their healthcare team. ${ }^{36} 37$

In a Norwegian study, the importance of taking time and effort to learn more about the value of CAM therapies has been emphasised. ${ }^{38}$ A qualitative study ${ }^{39}$ concludes that physicians have limited knowledge about the occurrence of possible interactions. Breisameter ${ }^{40}$ identifies ethical problems regarding the doctors' inability to provide information about the risks of using CAM together with conventional care.

On the other hand, CAM practitioners' beliefs and counselling practices on how to combine the two treatment 
worlds safely have not been explored. In Norway, the CAM profession is totally unregulated, and CAM practitioners may practice as long as they do no harm. This vague regulation of the CAM profession increases the chance of indirect risk and thereby threatens patient safety. ${ }^{25}$ It is reasonable to assume that CAM practitioners' knowledge of conventional medicine vary from no formal medical education to being fully trained physicians who have added some CAM modalities to their armamentarium. ${ }^{1641}$

The current non-communication between CAM and conventional professionals leaves it up to the patients themselves, who are in a vulnerable situation, to choose how to best integrate the two worlds of therapy. ${ }^{4} 1427$ Conventional healthcare providers may believe that to reduce risk, it is best to advise patients not to use CAM in combination with conventional treatment. However, a study ${ }^{14}$ demonstrated that patients may decline conventional medicine if they feel rejected when they want to discuss possible CAM treatment with their general practitioner (GP) or oncology expert.

It should be possible to support patients in making safe decisions about combining CAM with conventional care. $^{42}$ However, the large difference between the two worlds of therapy and the complexity of the issue makes this a challenging task. Conventional and CAM providers differ regarding treatment concepts, philosophies and diagnostic procedures leading to different models of disease causality and treatment practice. ${ }^{18}$ These differences likely influence the practitioners' conceptualisation of benefits and risks, making shared recommendations to patients unlikely.

There is little previous knowledge about how healthcare providers gather and seek information about CAM, and whether the perceptions and assessments of risk are equally understood by oncology experts, GPs, CAM practitioners and patients. ${ }^{39}$ The overarching question is, then, how healthcare providers in the conventional and the CAM fields can better support patients in making informed choices about CAM in cancer care. In this study, an interactive shared decision-making (SDM) tool $^{43}$ will be developed to enable patients and health professionals to make safe health choices.

\section{AIMS OF THE STUDY}

The global aim of this research project is to reduce risk and enhance safety for patients who want to combine conventional medicine with CAM in cancer care. To achieve this, we will:

Delineate, compare and evaluate perceptions and clinical experience of communication about direct and indirect risk situations among oncology experts (doctors and nurses), GPs and CAM practitioners (masseurs, acupuncturists, hands on healers and reflexologists/zone therapists).

To accomplish this, we will perform three individual studies:
Study 1: Perform a literature review of the qualitative research literature in the field. In this literature review the aim is to examine the qualitative research literature on the perception of and communication about the risk of complementary therapies among oncology experts (doctor and nurses), healthcare physicians and complementary providers who care for patients with cancer. The included studies will be summarised into different risk situations.

Study 2: Develop, pilot and implement a large-scale survey among oncology experts, GPs and CAM practitioners in Norway. The following research questions will be addressed in the mixed method survey pilot, and the large-scale survey:

A. Is there a difference among the four professional groups in how they gather information about CAM?

B. Is there a difference among the four professional groups in how they recognise direct and indirect risk situations in clinical practice? What kind of risk assessment tools do they use for this purpose? What procedure is followed when in doubt of medical diagnosis or when to refer to other healthcare interventions?

C. According to the study participants, what constitutes enough evidence on efficacy and safety to recommend a CAM modality?

D. Are there differences among the four professional groups in how they deal with patients who delay or decline conventional treatment?

E. Are there differences among the four groups in how they experience communication with their patients about CAM? What do practitioners on both sides think about risk and safety and the consequences of combining both treatment systems in cancer care?

Study 3: Guided by the survey results, design and develop an SDM tool for healthcare providers to use for guiding patients to make safe CAM decisions that are in line with the patients' health goals. We will draw on CAM information available through CAM-Cancer.org and Nifab.no. Both web pages are operated by the National Research Center in Complementary and Alternative Medicine (NAFKAM), the Arctic University of Norway, Troms $\varnothing$, Norway. We also have qualitative data available from different studies on patients with cancer. ${ }^{39}{ }^{44}$ These data will be incorporated in the tool. When designing the tool, we will cooperate with The Norwegian Centre for Integrated Care and Telemedicine at UNN-HF. They will develop a $\beta$-version of a tool to support decision-making. The tool will be published on Internet and will be ready for patients and healthcare providers to use. Telemedicine will operate the technical version of the SDM tool. Below is the flow chart of the study (figure 2).

\section{METHODS AND ANALYSIS}

Study 1: literature review

The aim of the literature review is to map the qualitative research literature about risk communication and 


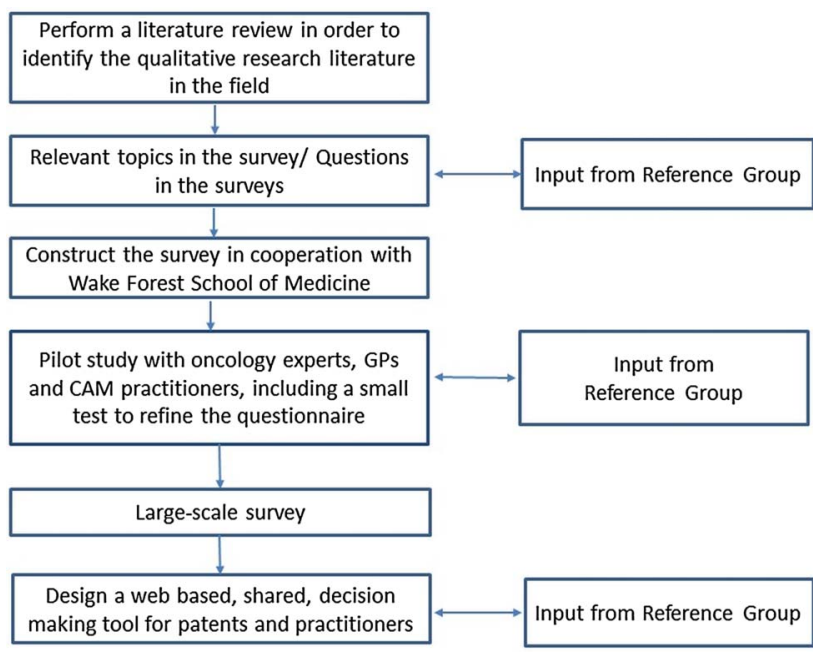

Figure 2 Flow of activities in this research project. CAM, complementary and alternative medicine; GP, general practitioner.

perceptions of complementary therapies among healthcare providers. We will include qualitative studies in this review as this approach can help researchers to gain access to the view of participants, and it contributes to a deeper understanding and thorough knowledge in health and well-being, especially in situations in which we have limited previous knowledge of our phenomenon of interest. ${ }^{45} 46$

The searches will be performed in databases such as AMED, CINAHL, MBASE, MEDLINE/PubMed and PsycINFO. The PEO (Population, Exposure and Outcome) format will be used. PEO is a tool used to formulate questions about qualitative research, and the search strategy will include keywords such as risk perception; risk communication; decision making; cancer care; Complementary and alternative medicine. MeSH-terms and truncation symbols will be used when available. The searches will be combined with manual searches in journals of interest and reference lists, in addition to abstracts and keywords. The inclusion will comprise qualitative studies (individual and group interviews, opinion of an expert and literature reviews) investigating communication and perception about risk of complementary therapies among conventional and complementary providers. However, qualitative studies that have an added quantitative component, for example, a questionnaire in the design (mixed design) will be included in the analysis. Quantitative studies (such as randomised controlled trials and observational studies) and evidence-based guidelines will be excluded.

\section{Theoretical framework}

We will draw on theories about risk in healthcare which, are described in the introduction, and interprofessionals and patient-centred communication (PPC). Clear and appropriate communication and interdisciplinary collaboration are critical to the delivery of quality care for the complex patients in today's healthcare settings. ${ }^{47}$ Effective communication may contribute to more confidence in the health provider and increased adherence to follow evidence-based recommendations and avoidance of negative interactions between conventional and complementary treatments. ${ }^{48}$ PPC is the set of skills and behaviours used by healthcare providers to promote a relationship in which patients actively participate as partners in healthcare decision-making and management. ${ }^{48-50}$ These theories will assist us in designing and conducting the study phases and interpreting the study findings.

\section{Study 2: pilot survey}

Prior to the main large-scale study, we plan to conduct a pilot study. The purpose is to test the data collection for face and content validity. ${ }^{51}$ Six participants $(n=6)$, including one oncology doctor, one nurse, one GP and three CAM providers, will be invited to participate in a Think-aloud session, ${ }^{52}$ which involves participants reporting their thoughts out loud as they complete the questionnaire. They will be asked to say whatever they are thinking, doing or looking at as they perform this task. The think-aloud session will provide us with information regarding whether any items are misunderstood, whether people answer in a meaningful way or whether they get bored or confused part way through. The questionnaire will be revised accordingly.

Then, 40 participants (10 oncology doctors, 10 oncology nurses, $10 \mathrm{GPs}$ and $10 \mathrm{CAM}$ providers) will complete the instrument and several other sets of questions to establish construct validity. ${ }^{51}$ The results from this questionnaire will be compared to the Holistic Complementary and Alternative Medicine Questionnaire (HCAMQ) and the Complementary and Alternative Medicine Beliefs Inventory (CAMBI) ${ }^{53}{ }^{54}$ Both are validated questionnaires including concepts like CAM beliefs and holistic health beliefs. These two factors represent distinct CAM constructs and will be used to distinguish CAM attitudes from conventional attitudes among the respondents. The oncology experts needed for the pilot study will be recruited through two wards at the University Hospital in North Norway (UNN). The study participants will be contacted by email or postal mail and invited to participate. The CAM providers will be recruited through private clinics in the Troms and Nordland county.

A reference group consisting of one oncology nurse, one GP and two CAM practitioners will assist the research team in testing the validity of the questionnaire. They will complete and comment on the instrument before the start of the pilot study.

\section{Study 2: large-scale survey}

\section{Inclusion criteria}

Oncology doctors and nurses, GPs and CAM providers who are currently practicing and members of a professional association, and have clinical experience with 
current or previously diagnosed patients with cancer are eligible for the study. Being a member of a professional association ensures high professional standards of medical and/or CAM skills among the participants. According to a Norwegian study from 2013, ${ }^{7}$ the four most popular CAM modalities used by Norwegian cancer survivors were massage $(10.5 \%)$, acupuncture $(7.6 \%)$, hands on healer $(4.8 \%)$ and reflexology $(3.2 \%)$. This information was the rationale for choosing these particular CAM participants in the study.

\section{Exclusion criteria}

Allopathic and CAM providers who have no clinical experience with current or previously diagnosed patients with cancer are ineligible for the study.

\section{Participants}

We will include one-hundred oncology doctors and 100 oncology nurses, working at the following four hospitals: The University Hospital of North-Norway (UNN), Tromso; St. Olav Hospital, Trondheim; Haukeland University Hospital, Bergen; and Norwegian Radium Hospital, Oslo. Furthermore, we will include 100 GPs and 400 CAM providers (100 masseurs, 100 acupuncturists, 100 hands on healers, 100 reflexologists/zone therapists) working in private clinics throughout the country.

\section{Recruitment}

The GPs and the oncology doctors will be recruited through The Norwegian Medical Association and The Union for Oncologists. The oncology nurses and the CAM providers will be recruited through The Norwegian Nurses Organization, The Association for Alternative Provider Organizations (Saborg), The Norwegian Acupuncture Association and The Norwegian Healer Association. We will ask the associations to provide us with a list of their members. The lists will be randomised by the study team. The participants will be offered a gift card as compensation for time spent responding to the study questionnaire. In order to increase the response rate among the GPs and oncology doctors, the gift card incentive will be somewhat higher for them. ${ }^{52}$

\section{Data collection}

To boost the questionnaire response rate as much as possible, a mixed mode including postal mail and email will be used. ${ }^{52}$ A standard introductory letter will be sent to all allopathic and CAM providers identified for inclusion. This letter will inform the recipient that he or she will receive a request to help with an important study. We will use a recognised and respected logo from the Arctic University of Norway and The Northern Norway Regional Health Authority on the stationery and envelopes, and the letters will be cosigned by a well-known physician. One week following the mailing of this letter, emails will be sent to all potential participants with a link to the Internet survey. The survey will be administered through a secure web application designed for online surveys. ${ }^{55}$ We will use a function that enables the research team to identify whether each person completes some or all of the survey, but prevents the research team from seeing any participant's identity, thereby providing anonymity. For those providers who do not have email or have limited access to Internet, a questionnaire will be sent by postal mail. After a week, a 'thank you' or a reminder email will be sent to the included providers. Finally, 1 week later a replacement questionnaire and a reminder letter with a link to the survey will be sent to the non-responders, including options to complete the questionnaire either by mail or email. The study participants who have completed the questionnaire will be asked to click on a link at the end of the questionnaire confirming whether they will like to receive a gift card or not. If they wish, a gift card will be sent to them by mail (table 1 ).

\section{Power calculation}

In order to identify any possible difference between the two groups of providers (conventional vs CAM), a power calculation was performed. The four groups to be studied are oncology experts (doctors and nurses), GPs and CAM practitioners. In Norway there are approximately 200 oncologists, 500 oncology nurses, 5500 GPs and an estimated 2100 CAM practitioners. Some providers, particularly oncologists and oncology nurses, may practice in the same facility and thereby share beliefs about conventional and CAM cancer treatment. This 'clustering' is incorporated into power calculations.

Power calculations are based on the question, 'Do you think CAM modalities can interact with conventional cancer treatments?' In our calculations, we presume that CAM providers will be highly likely to respond 'no' and that conventional providers will be less likely to respond 'no'. We calculate power for several different scenarios

\begin{tabular}{|c|c|c|}
\hline Week & Mail preference & Web preference \\
\hline 1 & $\begin{array}{l}\text { Standard introducing } \\
\text { letter }\end{array}$ & $\begin{array}{l}\text { Standard introducing } \\
\text { postal letter }\end{array}$ \\
\hline 2 & $\begin{array}{l}\text { Invitation letter } \\
\text { including consent } \\
\text { statement, mail } \\
\text { questionnaire, incentive } \\
\text { and return envelope }\end{array}$ & $\begin{array}{l}\text { Invitation email letter } \\
\text { including consent } \\
\text { statement, link to the } \\
\text { survey, incentive and } \\
\text { web survey instructions }\end{array}$ \\
\hline 3 & $\begin{array}{l}\text { Thank you postcard or } \\
\text { reminder postcard }\end{array}$ & $\begin{array}{l}\text { Thank you or reminder } \\
\text { email with link to the } \\
\text { survey }\end{array}$ \\
\hline 4 & $\begin{array}{l}\text { Replacement } \\
\text { questionnaire and } \\
\text { return envelope with } \\
\text { cover letter including } \\
\text { link to the survey for } \\
\text { web options to the } \\
\text { non-responders }\end{array}$ & $\begin{array}{l}\text { Reminder email to the } \\
\text { non-responders with link } \\
\text { to survey and web } \\
\text { survey instructions } \\
\text { accompanied by mail } \\
\text { questionnaire and return } \\
\text { envelope for the mail } \\
\text { option }\end{array}$ \\
\hline
\end{tabular}


Table 2 Scenarios for $90 \%$ power to detect a difference between conventional and CAM based on the question: 'Do you think CAM modalities can interact with conventional cancer treatments?'

\begin{tabular}{|c|c|c|c|c|c|c|}
\hline \multicolumn{7}{|l|}{ Proportion 2} \\
\hline \multirow[b]{2}{*}{ Proportion 1} & \multicolumn{2}{|l|}{0.7} & \multicolumn{2}{|l|}{0.8} & \multicolumn{2}{|l|}{0.9} \\
\hline & $\begin{array}{l}\text { N/Group } \\
\text { ICC }=0.0\end{array}$ & $\begin{array}{l}\text { N/Group } \\
\text { ICC }=0.2\end{array}$ & $\begin{array}{l}\text { N/Group } \\
\text { ICC }=0.0\end{array}$ & $\begin{array}{l}\text { N/Group } \\
\mathrm{ICC}=0.2\end{array}$ & $\begin{array}{l}\text { N/Group } \\
\mathrm{ICC}=0.0\end{array}$ & $\begin{array}{l}\text { N/-Group } \\
\mathrm{ICC}=0.2\end{array}$ \\
\hline 0.3 & 31 & 56 & 19 & 34 & 12 & 22 \\
\hline 0.4 & 56 & 101 & 30 & 54 & 17 & 31 \\
\hline 0.5 & 124 & 223 & 52 & 94 & 26 & 47 \\
\hline 0.6 & 477 & 856 & 109 & 196 & 42 & 76 \\
\hline
\end{tabular}

Scenarios are based on proportions responding negatively to the question and are presented with no intra class correlation (ICC) and ICC equal 0.2 and a cluster size of 5 .

CAM, complementary and alternative medicine.

of response to the question, with and without clustering taken into account (table 2). With a moderate difference between the two groups (CAM vs conventional providers) in response to the question (CAM providers with a $70 \%$ proportion and Conventional providers with $50 \%), 124$ respondents are needed per group to have $90 \%$ power to detect a difference. When clustering is taken into account and a cluster size of 5 , with a moderate/high interclass correlation of 0.2 used, 223 per group (conventional and CAM providers) are needed to have $90 \%$ power.

However, in order to perform within group comparisons we will include 300 conventional providers (100 oncology doctors, 100 oncology nurses, $100 \mathrm{GPs})$ and 400 CAM providers (100 masseurs, 100 acupuncturists, 100 hands on healers, 100 reflexologists/zone therapists), a total sample size of 700 . Table 3 shows our projections for sample sizes, taking into account response screening rates.

\section{Measurements}

Table 4 shows the study measures including the main study concepts and some examples of questions from which these concepts will be constructed. The study measures are based on preliminary analysis from the meta-synthesis and results from the first meeting with the reference group where the participants were challenged to make questions related to the different concepts in the questionnaire.

\section{Statistical analyses}

The surveys will be a questionnaire based cross-sectional survey. The research questions mentioned above will be explored further in the questionnaire, and both closed and open-ended questions will be used. Responses to the open-ended questions will be categorised into nominal or ordinal scales. The guiding principle of the analyses will be performed by descriptive statistics of the perceptions present overall and comparisons of the four practitioner groups. $\chi^{2}$ tests and logistic regression will be used for analysing binary dependent variables, and analysis of variance will be used analysing continuous, dependent variables. Quantitative data will be analysed using the SPSS V.19.0 for Windows.

\section{Study 3: A web-based decision-making tool}

In cooperation with The Norwegian Centre for Integrated Care and Telemedicine at the University Hospital of North-Norway, an SDM tool to support decision-making about CAM and conventional care for patients with cancer will be developed. The tool will be published on the Internet and ready to use for patients and healthcare providers. The Norwegian Centre for Integrated Care and Telemedicine will operate the technical version of the SDM tool.

Table 3 Targeted response and screening rates for each group of providers and the numbers to be contacted to arrive at the sample sizes

\begin{tabular}{|c|c|c|c|c|c|}
\hline Type of providers & $\begin{array}{l}\text { Number of } \\
\text { available }\end{array}$ & $\begin{array}{l}\text { Number of } \\
\text { contacted }\end{array}$ & $\begin{array}{l}\text { Response } \\
\text { rate }(\%)\end{array}$ & $\begin{array}{l}\text { Screened out for } \\
\text { not treating patients } \\
\text { with cancer }(\%)\end{array}$ & $\begin{array}{l}\text { Final } \\
\text { sample } \\
\text { size }\end{array}$ \\
\hline Oncology doctors & 200 & 200 & 50 & 0 & 100 \\
\hline Oncology nurses & 500 & 200 & 50 & 0 & 100 \\
\hline General practitioners & 5.500 & 200 & 50 & 0 & 100 \\
\hline Acupuncturists & 761 & 400 & 50 & 50 & 100 \\
\hline Masseurs & 687 & 400 & 50 & 50 & 100 \\
\hline Reflexologists & 290 & 290 & 50 & 50 & 100 \\
\hline Hands on healers & 258 & 400 & 50 & 50 & 100 \\
\hline
\end{tabular}


Table 4 Study measures

\begin{tabular}{llll}
\hline Study concepts & Constructed from the following example questions & $\begin{array}{l}\text { Type of } \\
\text { variable }\end{array}$ & Dichotomous \\
\hline Risk perceptions & CAM should only be used as a last resort when conventional medicine has & nothing to offer & Order \\
& How often do you ask your patients if they use CAM and/or conventional & categories \\
Risk communication & medicine? & Do you think that CAM modalities can interact with conventional medicines? & Dichotomous \\
& Is the lack of regulation of the CAM profession risky for the patients? & Dichotomous \\
Direct risk situations & Do you seek information regarding CAM cancer treatment? & Dichotomous \\
Indirect risk situations & Do you seek information regarding conventional cancer treatment? & Dichotomous \\
Information regarding CAM & & &
\end{tabular}

\section{ETHICS}

The participants will receive a written document describing the purpose and consequences of participating in the study. They will be informed of the possibility to withdraw from the study followed by deletion of all data registered. The returned and completed questionnaire will be considered consent to participate in the study. The study does not need approval from The Regional Committee for Medical and Health Research Ethics, according to Norwegian legislation, because all participants are healthcare professionals. All data will be archived according to established procedures and REDCap safety procedures. No information that may be traced back to individuals will be published.

\section{DISSEMINATION}

The results of this research project will be disseminated to patients with cancer, healthcare professionals in both conventional care and CAM, the Norwegian Cancer Society, public health associations and various CAM practitioner organisations. The scientific work will be published in peer-reviewed journals, and orally presented at national and international conferences. The published results will be communicated through The National Information Center for Complementary and Alternative Medicine's (NIFAB) web portal. NIFAB is a part of The National Research Center in Complementary and Alternative Medicine (NAFKAM) and its web portal http://www.nifab.no is frequently visited. The results will be communicated to the relevant organisations through direct contact.

\section{PUBLICATION POLICY}

The results of the study will be published in appropriate journals regardless of outcome. The study will be implemented and reported in accordance with the recommendations of the STROBE checklist.

\section{DISCUSSION}

This protocol presents three studies designed to delineate, compare and evaluate perceptions and clinical experience of communication with direct and indirect risk situations among different professionals of healthcare providers in cancer care. The global aim is to reduce risk and enhance safety for patients who want to combine conventional medicine with CAM in cancer care. The project will increase knowledge about how CAM and conventional health providers understand the potential benefits and risks of combining both treatment systems in cancer care. Such information is essential to bridge the communication gap between patients and their healthcare providers. ${ }^{35} 56$ Lack of communication and coordination between different parts of the healthcare system are major threats to patient safety. ${ }^{39}$ This general tool can pave the way for more disease-specific tools that highlight the issue of CAM-conventional direct and indirect risks relevant to these patient groups. ${ }^{43}$ It is, therefore, innovative and useful for public health authorities as it will improve patient engagement and the quality of healthcare.

Acknowledgements The authors are thankful to Joanne Sandberg for valuable comments when finalising the manuscript and Haiying Chen for advice regarding the sample size calculation. The authors would also like to thank Åsa Sohlén and Jane Ekelund for their indispensable technical support.

Contributors TS, FM and GB initiated the project. TS, FM, SAQ, TAA, AS, AK and $\mathrm{GB}$ contributed to conceptualisation and design of the study and all revised this manuscript critically for important intellectual content. All authors read and approved the final manuscript.

Funding This research was funded by The Northern Norway Regional Health Authority, Tromsø, Norway (grant number HST1190-14). This research project will be financed according to the budget stated in the application document. The SDM tool will be internally funded by NAFKAM.

Competing interests None declared.

Provenance and peer review Not commissioned; externally peer reviewed.

Open Access This is an Open Access article distributed in accordance with the Creative Commons Attribution Non Commercial (CC BY-NC 4.0) license, which permits others to distribute, remix, adapt, build upon this work noncommercially, and license their derivative works on different terms, provided the original work is properly cited and the use is non-commercial. See: http:// creativecommons.org/licenses/by-nc/4.0/

\section{REFERENCES}

1. Ben-Arye E, Frenkel M, Margalit RS. Approaching complementary and alternative medicine use in patients with cancer: questions and challenges. J Ambul Care Manage 2004;27:53-62.

2. Cassileth BR, Schraub S, Robinson E, et al. Alternative medicine use worldwide. Cancer 2001;91:1390-3. 
3. Yates JS, Mustian KM, Morrow GR, et al. Prevalence of complementary and alternative medicine use in cancer patients during treatment. Support Cancer Care 2005;13:806-11.

4. Molassiotis A, Fernandez-Ortega P, Pud D, et al. Use of complementary and alternative medicine in cancer patients: a European survey. Ann Oncol 2005;16:655-63.

5. LOV-2003-06-27-64 Lov om alternativ behandling av sykdom mv (English translation: Act relating to the alternative treatment of disease, illness, etc, Helse- og omsorgsdepartementet, 2002-2003 Sess). 2003.

6. Horneber M, Bueschel G, Dennert G, et al. How many cancer patients use complementary and alternative medicine: a systematic review and metaanalysis. Integr Cancer Ther 2012;11:187-203.

7. Kristoffersen AE, Norheim AJ, Fonnebo VM. Complementary and alternative medicine use among Norwegian cancer survivors: gender-specific prevalence and associations for use. Evid Based Complement Alternat Med 2013;2013:318781.

8. Molassiotis A, Scott JA, Kearney N, et al. Complementary and alternative medicine use in breast cancer patients in Europe. Support Care Cancer 2006;14:260-7.

9. Verhoef MJ, Trojan L, Armitage GD, et al. Complementary therapies for cancer patients: assessing information use and needs. Chronic Dis Can 2009;29:80-8.

10. Jacobson JS, Workman SB, Kronenberg F. Research on complementary/alternative medicine for patients with breast cancer: a review of the biomedical literature. J Clin Oncol 2000;18:668.

11. Han E, Johnson N, Delamelena T, et al. Alternative therapy used as primary treatment for breast cancer negatively impacts outcomes. Ann Surg Oncol 2011;18:912-16.

12. Risberg T, Bremnes RM, Vickers A, et al. [Does use of alternative medicine aggravate the survival prognosis in cancer?]. Tidsskr Nor Laegeforen 2003;123:628-30.

13. Wiesener S, Falkenberg T, Hegyi G, et al. Legal status and regulation of CAM in Europe. Forsch Komplementärmed und Klass Naturheilkd 2012;19(Suppl 2):29-36

14. Salamonsen A. Doctor-patient communication and cancer patient's choice of alternative therapies as supplement or alternative to conventional care. Scand J Caring Sci 2013;27:70-6.

15. Jeannie LH, Falkenberg T, Hegyi G, et al. Continuity of care: a multidisciplinary review. BMJ 2003;327:1219-21.

16. Stub T, Alraek T, Salamonsen A. The Red flag! Risk assessment among medical homeopaths in Norway: a qualitative study. BMC Complement Altern Med 2012;12:150.

17. Macpherson $\mathrm{H}$, Kaptchuk T. Acupuncture in practice: case history insights from the west. Edinburgh: Churchill Livingstone, 1997.

18. Singer $\mathrm{M}, \mathrm{Baer} \mathrm{H}$. Introducing medical anthropology. A discipline in action. 2nd edn. Plymouth: AltaMira Press, 2012.

19. Maciocia G. The practice of Chinese medicine. Edinburgh: Churcill Livingstone, 1994.

20. Berger S, Braehler E, Ernst J. The health professionalpatient-relationship in conventional versus complementary and alternative medicine. A qualitative study comparing the perceived use of medical shared decision-making between two different approaches of medicine. Patient Educ Couns 2012;88:129-37.

21. Davis EM. Risky business: medical discourse, breast cancer, and narrative. Qual Health Res 2008;18:65-76.

22. Runciman $\mathrm{W}$, Hibbert $\mathrm{P}$, Thomson $\mathrm{R}$, et al. Towards an international classification for patient safety: key concepts and terms. Int J Quality in Health Care 2009;21:18-26.

23. Fisher $\mathrm{P}$, Dantas $\mathrm{F}$, Rampes $\mathrm{H}$. The safety of homeopathic products $J$ R Soc Med 2002:95:474-6.

24. Ernst E. Towards a scientific understanding of the placebo effects. In: Peter D, ed. Understanding the placebo effect in complementary medicine. London: Churchill Livingstone, 2001:17-29.

25. Stub T. Safety of Treatment Provided by Homeopaths Homeopathic Aggravations, Adverse effects and Risk Assessment [PhD thesis]. Tromsø: UiT The Arctic University of Norway, Tromsø, 2013.

26. Bao PP, Lu W, Cui Y, et al. Ginseng and Ganoderma lucidum use after breast cancer diagnosis and quality of life: a report from the Shanghai breast cancer survival study. PLOS ONE 2012;7:e39343.

27. Ma H, Sullivan-Halley J, Smith AW, et al. Estrogenic botanical supplements, health-related quality of life, fatigue, and hormone-related symptoms in breast cancer survivors: a HEAL study report. BMC Complement Altern Med 2011;11:109.

28. Harris RM, Wood DM, Bottomley L, et al. Phytoestrogens are potent inhibitors of estrogen sulfation: implications for breast cancer risk and treatment. J Clin Endocrinol Metab 2004;89:1779-87.

29. Wu WH, Liu L-Y, Chung C-J, et al. Estrogenic effect of yam ingestion in healthy postmenopausal women. J Am Coll Nutr 2005;24:235-43.
30. Wu AH, Stanczyk FZ, Martinez C, et al. A controlled 2-mo dietary fat reduction and soy food supplementation study in postmenopausal women. Am J Clin Nutr 2005;81:1133-41.

31. Wardle JL, Adams J. Indirect risks of complementary and alternative medicine. In: Adams J, et al., eds. Traditional, complementary and integrative medicine. Hampshire; Palgrave Macmillian, 2012:212-19.

32. Tovey P, Broom A. Oncologists' and specialists cancer nurses' approaches to complementary and alternative medicine and their impact on patient action. Soc Sci Med 2007;64:2550-64.

33. Lindring i nord, et al Håndbok i lindrende behandling (Handbook for palliative care). Tromsø: Universitetssykehuset Nord-Norge (University Hospital of North Norway).

34. Verhoef MJ, Boon HS, Page SA. Talking to cancer patients about complementary therapies: is it the physicians's responsibility? Current Oncology 2008;15:18-23.

35. Deng GE, Frenkel M, Cohen L, et al. Evidence-based clinical practice guidelines for integrative oncology: complementary therapies and botanicals. J Soc Integr Oncol 2009;7:85-120.

36. Navo MA, Liu L-Y, Chung C-J, et al. An Assessment of the utilization of complementary and alternative medication in women with gynecologic or breast malignancies. J Clin Oncol 2004;22:671-7.

37. Richardson MA, Sanders T, Palmer JL, et al. Complementary/ alternative medicine use in a comprehensive cancer center and the implications for oncology. J Clin Oncol 2000;18:2505-14.

38. Risberg T, Kolstad A, Bremnes Y, et al. Knowledge of and attitudes toward complementary and alternative therapies: a national multicentre study of oncology professionals in Norway. Eur J Cancer 2004;40:529-35.

39. Salamonsen A. Mind the gap! lay and medical perceptions of risks associated with the use of alternative treatment and conventional medicine. Forsch Komplementmed 2015;22:24-9.

40. Breisameter $\mathrm{C}$. Medical decision-making and communication of risks: an ethical perspective. J Med Ethics 2010;36:349-52.

41. Stub T, Salamonsen A, Alræk T. Is it possible to distinguish homeopathic aggravation from adverse effects? A qualitative study Forsch Komplementärmed Klass Naturheilkd 2011;19:13-19.

42. Gamst A, Haahr N, Kristoffersen AE, et al. Integrative care and bridge building among health care providers in Norway and Denmark. J Altern Complement Med 2006;12:141-6.

43. Elwyn G, Edwards A, Kinnersley P, et al. Shared decision making and the concept of equipoise: the competences of involving patients in healthcare choices. Br J Gen Pract 2000;50:892-9.

44. Salamonsen A, Kruse T, Eriksen SH. Modes of embodiment in breast cancer patients using complementary and alternative medicine. Qual Health Res 2012;22:1497-512.

45. Kvale S. Det kvalitative forskningsintervju. Oslo: Gyldendal Norsk Forlag AS, 2001.

46. Fontana $\mathrm{A}$, Frey $\mathrm{JH}$. The interview from neutral stance to political involvement. In: Knigth V, ed. Collecting and interpreting qualitative materials. London: Sage Publications, 2008:115-59.

47. Rosenstein AH, O'daniel M. Original research: disruptive behavior and clinical outcomes: perceptions of nurses and physicians: nurses, physicians, and administrators say that clinicians' disruptive behavior has negative effects on clinical outcomes. Am J Nurs 2005; 105:54-64.

48. Saha S, Beach MC. The impact of patient-centered communication on patients' decision making and evaluations of physicians: a randomized study using video vignettes. Patient Educ Couns 2011;84:386-92.

49. Roter DL, Hall JA. Doctors talking with patients, patients talking with doctors. Westport: Auburn House, 1992.

50. Engel GL. The need for a new medical model: a challenge for biomedicine. Science 1977;196:129-36.

51. Peat J. Health science research. A handbook of quantitative methods. London: SAGE Publications, 2002.

52. Dillman DA, Smuty JD, Christian LM. Internet, mail and mixed-mode surveys. The tailored design method. 3rd edn. New Jersey: John Wiley \& Sons, Inc, 2009.

53. Hyland ME, Lewith GT, Westoby C. Developing a measure of attitudes: the holistic complementary and alternative medicine questionnaire. Complement Ther Med 2003;11:33-8.

54. Bishop FL, Yardley L, Lewith G. Developing a measure of treatment beliefs: the complementary and alternative medicine beliefs inventory. Complement Ther Med 2005;13:144-9.

55. Harris RA, Taylor R, Thielke R, et al. Research electronic data capture (REDCap)—a meta-driven methodology and workflow process for providing translational research informatics support. $J$ Biomed Inform 2009;42:377-81.

56. Cassileth BR, Taylor R, Thielke R, et al, American College of Chest Physicians. Complementary therapies and integrative oncology in lung cancer. ACCP evidence-based clinical practice guidelines (2nd edition). Chest 2007;132:340-54. 